\section{Message from Co-Editor-in-Chief}

John A. Elefteriades, M.D., F.I.C.A. ${ }^{1}$

${ }^{1}$ Aortic Institute, Yale University School of Medicine, New Haven, Connecticut

Int J Angiol 2012;21:3-4.

It is with great pleasure that I write to welcome you to the newly invigorated International Journal of Angiology.

The journal now has a new Publisher and an enhanced Editorial Board. It has fully entered the electronic era for submission and access.

Past, present, and future articles published in the journal are now cited and available on PubMed. This will encourage both young and established authors to submit their work for consideration for publication.

I personally am honored to take on the role of Co-Editor-inChief beside the distinguished Dr. John Chang. We will strive for early feedback decisions on submitted abstracts as an additional "draw" for authors with work to be submitted.

This journal has traditions that keep it interesting and special, and these will continue. Among my favorite features is the opportunity to read in the journal about a wide range of topics not covered in single-specialty journals. Specifically, I enjoy being able to read about vascular surgery, cardiac surgery, cardiac and blood vessel pathology and physiology, and interventional techniques. I especially enjoy the fact that papers published in the journal often represent early, exciting, and groundbreaking work in the germinal stages. One finds both clinical and basic science represented in the journal. I also appreciated the opportunity to learn from the superb review articles by specialists in

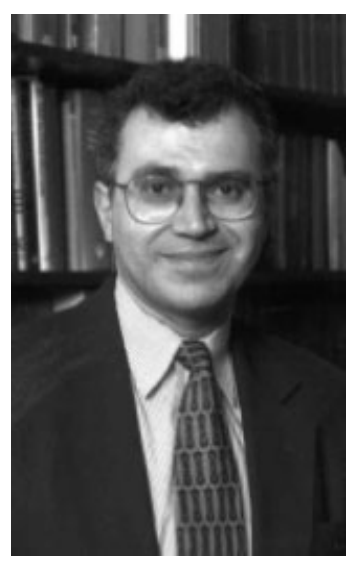

John A. Elefteriades, M.D., F.I.C.A. the affiliated disciplines.

From the outset, before it was fashionable, Dr. Chang and the other founders of the International Journal of Angiology recognized the inherently multidisciplinary nature of blood vessel disease and treatment and the benefits of collaboration between related specialties. This early recognition has certainly been vindicated in the current era of close collaboration between related specialties. This multidisciplinary approach forms the very core of the International Journal of Angiology.

Welcome to the newly revised journal. I hope you enjoy reading it as much as I do.
Address for correspondence and reprint requests John $A$.

Elefteriades, M.D., F.I.C.A., Aortic Institute, Yale University School of Medicine, P.O. Box 208039,

New Haven, CT 06520

(e-mail: john.elefteriades@yale. edu).
Copyright $\odot 2012$ by Thieme Medical Publishers, Inc., 333 Seventh Avenue, New York, NY 10001, USA. Tel: +1(212) 584-4662.
DOI http://dx.doi.org/ 10.1055/s-0032-1307447. ISSN 1061-1711. 